\title{
Evaluation of electrical resistivity tomography (ERT) for mapping the soil-rock interface in karstic environments
}

\author{
Qinbo Cheng ${ }^{1,2} \cdot \operatorname{Min~Tao}^{2} \cdot \mathrm{Xi} \mathrm{Chen}^{2,3} \cdot$ Andrew Binley $^{1}$ (1)
}

Received: 27 July 2018 / Accepted: 8 July 2019 / Published online: 19 July 2019

(c) The Author(s) 2019

\begin{abstract}
Rocky desertification is a significant threat in the karst regions of southwest China. Studies of soil distribution can contribute to protecting and recovering the fragile karst ecosystem that is prevalent in this region. With an underlying aim of being able to assess soil stocks in karstic environments, this study evaluates the use of electrical resistivity tomography (ERT) for delineating the soil-rock interface. Using a synthetic model (that recognizes the three-dimensional nature of the subsurface), experiments are performed to assess the impact of measurement errors and measurement configuration on recovery of the interface. The inverted results show that the accuracy of the delineation of the soil-rock interface decreases with the increase of measurement error and dipole spacing. The results also show the importance of reliable estimation of measurement errors. Field-based applications of ERT at five exposed profiles in southwest China are also reported. For the field data, three-dimensional modelling was necessary to account for the exposed face. The field experiments show that ERT can be effective at delineating the interface between soil and bedrock, but resolution can be limited due to the scale of features or lack of contrast between soil and bedrock. The method shows great promise as a means of assessing, in a non-invasive manner, the soil-bedrock interface, and, perhaps, more significantly, quantifying estimates of total soil stocks, as we seek to quantify the vulnerability or resilience of this important landscape to anthropogenic and natural stresses.
\end{abstract}

Keywords Electrical resistivity tomography $($ ERT) $\cdot$ Geophysics, Karst $\cdot$ Terra rossa $\cdot$ Critical zone

\section{Introduction}

Soils provide a matrix for vegetation, a supply of minerals and nutrients for plant growth, an essential medium that allows the exchange of water and gases between the surface and subsurface, a significant store of carbon and a habitat for insects and many other organisms (Miller 1953; Schoonover

This article is a part of Topical Collection in Environmental Earth Sciences on Characterization, Modeling, and Remediation of Karst in a Changing Environment, guest edited by Zexuan $\mathrm{Xu}$, Nicolas Massei, Ingrid Padilla, Andrew Hartmann, and Bill Hu.

Andrew Binley

a.binley@lancaster.ac.uk

1 Lancaster Environment Centre, Lancaster University, Lancaster LA1 4YQ, UK

2 State Key Laboratory of Hydrology, Water Resources and Hydraulic Engineering, Hohai University, Nanjing 210098, China

3 Institute of Surface-Earth System Science, Tianjin University, Tianjin, China and Crim 2015). Assessing the abundance or thickness of soil is, therefore, critical for the understanding numerous environmental and ecological processes and the impact of natural and anthropogenic-driven changes on many ecosystem services. In karstic environments, the soil thickness can be extremely heterogeneous, and rapidly evolving.

Karst landforms are formed from the dissolution of soluble rocks (such as limestone, dolomite, marlstone, and gypsum), which can lead to physical collapse of bedrock (sinkholes) and can often result in the development of the caves, springs, and underground rivers (Sweeting 1995; Goldscheider and Drew 2007). Erosion and suffosion processes (associated with subsidence sinkholes or doline formation via either collapse or subsidence) at, or near, the ground surface can result in complex soil profiles (Fig. 1).

The karst region of southwest China is one of the largest contiguous areas of karst globally, and covers $540,000 \mathrm{~km}^{2}$ (Hollingsworth 2009). In this area, the terrain undulates significantly because of the combination of bedrock dissolution and tectonic processes, enhanced by the warm and moist climate. The production rate of soil is low (about $2 \mathrm{~cm}$ per 


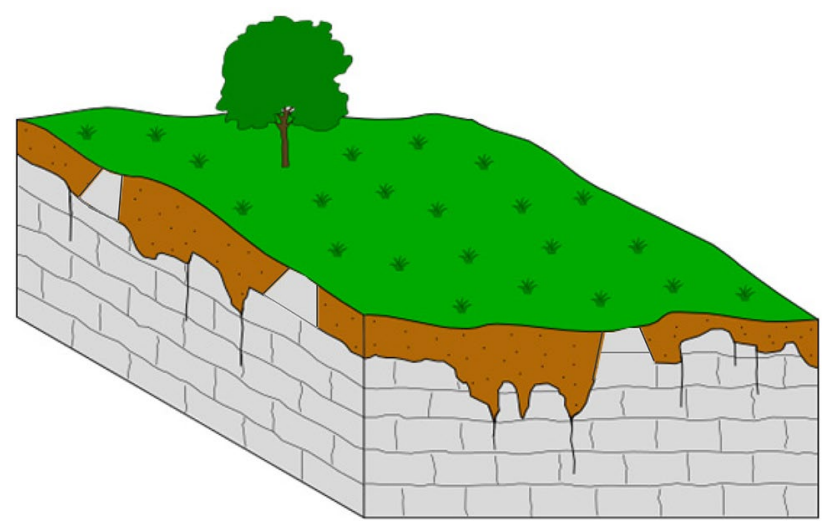

Fig. 1 Schematic diagram of the shallow soil-bedrock interface in karst

10,000 years), because the insoluble residue content in pure carbonate rocks is small (less than 5\%; Jiang et al. 2014). Moreover, there are high-intensity human activities such as deforestation, cultivation, and reclamation (Zhang et al. 2017) which have a significant impact on the soil profile. As a result, soil loss and rocky desertification is of major concern in this region (Wang et al. 2004, 2014; Zhou et al. 2012; Peng and Wang 2012).

Because of significant soil loss potential, the soil layer in hillslopes of karstic regions in southwest China is usually shallow, highly variable in thickness and sometimes discontinuous, as shown in Fig. 1. In the geographic area of study, here, soils are typically $20-40 \mathrm{~cm}$ thick in upper hillslopes and 50-150 cm thick at the foot of hillslopes (Peng and Wang 2012; Hu et al. 2015; Fu et al. 2016). Transportation and replacement of soil into dissolution features in the bedrock can result in complex soil profiles (Zhou et al. 2012; Wang et al. 2014; Merino and Banerjee 2008; Banerjee and Merino 2011).

Methods to assess soil thickness rapidly are, therefore, potentially extremely valuable in such regions, where soils are essential for many ecosystem services but also extremely vulnerable to changes in climate and land use. Given the high heterogeneity of soil profiles in karstic environments, traditional auger and excavation techniques are limited given their small measurement support volume. Recently, Yan et al. (2019) investigated the morphological characteristics and soil properties of shallow karst features in southwest China and highlight the need more rapid non-invasive methods to characterize such features. Here, we explore the use of electrical geophysical methods for mapping soil thickness in a shallow karst environment.

Over the past few decades, geophysical methods have emerged as effective measurement techniques for many hydrological studies (Binley et al. 2015). Such methods provide measurements of geophysical proxies for properties of interest. Ground penetrating radar (GPR), which relies on the 'echo sounding' of contrasts in soil electrical properties (e.g., at the soil-bedrock interface), have been used to assess soil thickness of large spatial scales (e.g., Wang et al. 2015; Xia et al. 2016; Zhang et al. 2013). However, the investigation depth of GPR is extremely limited, where soils are electrically conductive due to high clay and moisture content (Chalikakis et al. 2011; Zhou et al. 2012). Such soils are prevalent in southwest China; moreover, many soils contains high gravel content (i.e., fragments of limestone and dolostone), which produces interference signals (Wang et al. 2015), which can mask signals related to the soil-bedrock interface.

Electrical resistivity tomography (ERT) is a geophysical method that provides 2D and 3D images of the variation in electrical resistivity (inverse of electrical conductivity) using electrodes typically placed on the ground surface. ERT has been widely used in karstic environments. For example, Zhu et al. (2011) adopted a range of ERT methods (including time-lapse approaches) to locate karst conduits, and Carrière et al. (2013) and Martínez-Moreno et al. (2014) combined ERT and GPR to detect fractures and conduits in karst. However, most previous studies have focused on using ERT to detect the deep karst structures, such as sinkholes, caves and conduits. ERT also has potential for revealing the soil-bedrock interface and thus providing a means of quantifying soil stocks on complex bedrock topography, as the soil resistivity is commonly much lower than the carbonate rock resistivity (Chalikakis et al. 2011).

Zhou et al. (2000) attempted to use ERT to define depth to bedrock. However, they noted a large difference between their geophysical results and borehole logging. They attributed their failure to six causes: data quality; limitations of electrical methods; non-uniqueness of the modelling results; inaccuracy in the soil boring data; impact of three-dimensional geology; and complex geology in karst terrains.

Building on the experiences of the previous studies, this study explores the effectiveness of ERT to map shallow karst soil thickness at a number of sites in a region of southwest China. Rather than comparing field results to point measurements (as in previous studies), we exploit the availability of a number of roadway cuts with exposed profiles. We examine, for the first time, a comparison of ERT performance and visual observations of soil thickness, at a number of sites characteristic of the region. We also explore the impact of various measurement configurations and factors using a synthetic modelling study. The study is part of a larger investigation of critical zone processes within the karstic region of southwest China, which aims to assess threats to ecosystem services caused by changes in land use in the area. 


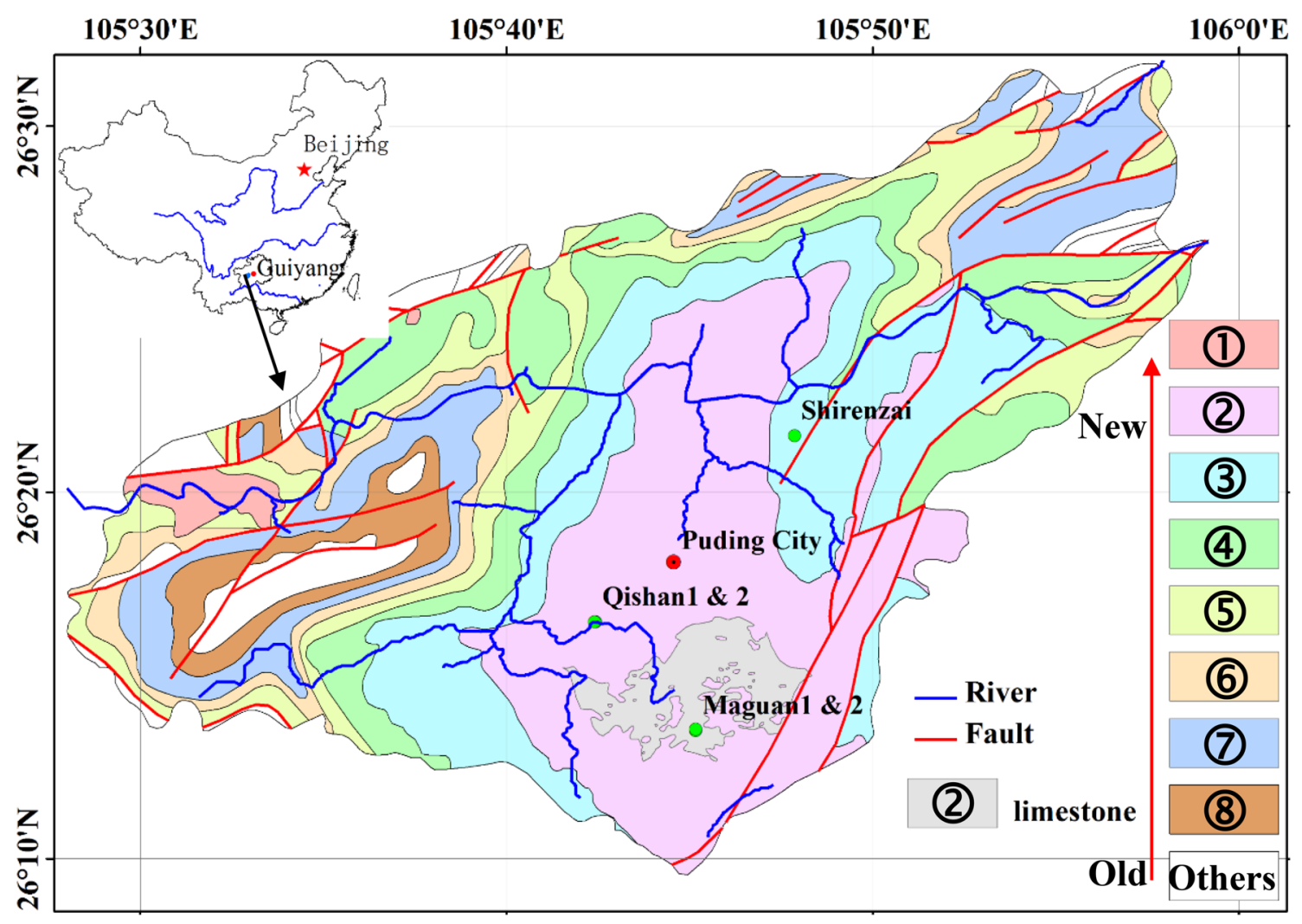

(1) Campanian, Upper, Cretaceous; Brick red conglomerate, gravel quartz sandstone and sandy mudstone; 90-921 m thickness. (2) Anisian, Middle, Triassic; from bottom to up, Dolomite with clay rock, Limestone and Dolomite; 1000-2000 m thickness. (3) Olennekian, Lower, Triassic; from bottom to up, off-white massive Dolomites, Muddy Dolomite, and Collapse Dolomite; 280-712 m thickness. (4) Induan, Lower, Triassic; from bottom to up, Limestone with clay rock, Limestone with shale and Lamellar Limestone; 110-580 m thickness. (5) Changhsingian and Wuchiapingian, Lopingian, Permian. (6) Capitanian, Guadalupian, Permian; Emeishan Basalt. (7) Wordian and Roadian, Guadalupian, Permian. (8) Pennsylvanian, Carboniferous.

Fig. 2 Location and geology map (1:500,000) of Puding County study area and the five selected survey profiles

\section{Study area}

The study sites are located in the Puding County, Guizhou Province, China (Fig. 2). Puding is located in the drainage divide between the Yangtze and Pearl river systems, of which $98 \%$ of the water flow is north to the Yangtze river. The terrain is sloped from the south and north part to the central valley (Sancha River). The average elevation is close to $1354 \mathrm{~m}$. The climate belongs to the Western Pacific Ocean subtropical monsoonal region, where average annual precipitation and temperature are $1378.2 \mathrm{~mm}$ and $15.1{ }^{\circ} \mathrm{C}$, respectively.

The main soil type is the red clay (terra rossa) formed by carbonate after its solution in hot, humid, and rainy climate conditions (Zhou et al. 2012). Given the local climate and hydraulic properties, this soil has a high water content, strong plasticity, relatively high mechanical strength and low compressibility (Zhou et al. 2012). Given these properties, the resistivity of clay soils (terra rossa) in the study area is relatively low (i.e., wet clays are electrically conductive).

The karst area of Puding accounts for $84 \%$ of the total area. The soil erosion modulus for the area is up to 3054 tons $/ \mathrm{km}^{2} /$ year. The rocky desertification area accounts for $35.8 \%$ and the desertification rate is up to 513 hectares/ year. In other words, bedrock desertification is extremely serious in Puding and its impact on, for example, agriculture and water quality, poses a great threat to local habitants.

Based on differences of bedrock types and covered soil thickness, five profiles with an exposed face were selected 
Table 1 Information about bedrock type, land use, soil thickness, and ERT survey line set of five profiles

\begin{tabular}{|c|c|c|c|c|c|c|c|}
\hline \multirow[t]{2}{*}{ ID } & \multirow[t]{2}{*}{ Bedrock type } & \multirow[t]{2}{*}{ Ground cover } & \multicolumn{2}{|c|}{ Soil thickness (m) } & \multicolumn{2}{|c|}{ ERT survey line } & \multirow{2}{*}{$\begin{array}{l}\text { Distance to } \\
\text { exposed face } \\
\text { (m) }\end{array}$} \\
\hline & & & Average & Variation & $\begin{array}{l}\text { Number of } \\
\text { electrodes }\end{array}$ & $\begin{array}{l}\text { Electrode spac- } \\
\text { ing }(\mathrm{m})\end{array}$ & \\
\hline 1 & Thick-bedded limestone & Bare & 0.90 & 0.50 & 48 & 0.30 & 0.64 \\
\hline 2 & & Corn & 1.12 & 0.40 & 96 & 0.30 & 0.72 \\
\hline 3 & Dolostone & Grass & 1.60 & 1.10 & 96 & 0.25 & 0.66 \\
\hline 4 & & Bare & 0.47 & 0.14 & 48 & 0.50 & 0.70 \\
\hline 5 & Laminar-bedded limestone & Corn & 0.78 & 0.51 & 96 & 0.20 & 0.72 \\
\hline
\end{tabular}

for ERT surveys. Two profiles on a thick-bedded limestone, two on dolomite, and one on lamellar limestone were selected. Detailed information about bedrock type, land use, soil thickness, and ERT survey of the five profiles is shown in Table 1.

\section{Methodology}

\section{ERT}

ERT is an active source geophysical method: pairs of electrodes in contact with the ground are used to create an electrical field (i.e., current is induced) and pairs of electrodes measure the voltage gradient away from the source. By carrying out such measurements in different geometrical configurations, it is possible to assess the resistivity of the subsurface. Traditionally, electrodes are laid out in the field along one line and a $2 \mathrm{D}$ representation of the resistivity beneath that line is derived. Using a 2D arrangement of electrodes on the surface, a 3D image can be assessed.

Different electrode configurations (the geometry of the quadrupole) are possible (Binley 2015). The Wenner, Schlumberger, and dipole-dipole configurations are the most popular (e.g., Kaufmann and Deceuster 2014; Binley 2015; Keshavarzi et al. 2017). Although the dipole-dipole configuration has, in comparison to others, a weak signal strength, it is the most effective for assessing lateral variation in resistivity (a likely characteristic of karst) in the shallow subsurface. In addition, many modern ERT measurement devices allow some level of multi-channel measurement using a dipole-dipole configuration, thus making this configuration efficient in the field.

The ERT inversion software (R2 and R3t) developed by Binley $(2013,2016)$ is used in this study for estimation of resistivity distribution. Field measurements were made using a Syscal Pro 96 (Iris Instruments, France), which can connect to 96 electrodes simultaneously, and collect 10 measurements on contiguous dipoles simultaneously. We adopted a typical 2D imaging configuration in the field, installing the electrode array a short distance from the exposed face to ensure that the observed face is a reasonable match to the image zone (Table 1, column of "Distance to exposed face (m)"). However, as dipoles are separated in an ERT survey, the footprint of the measurement increases, and thus, there is some inevitable impact of resistivity variation orthogonal to the line (i.e., away from the roadway cut face).

Resistivity images are computed from an inverse solution of the potential field problem. We used the commonly adopted Occam's inversion (see Binley and Kemna 2005) for the resistivity problem. This involves determining a smooth resistivity model that is consistent with the data. Alternatives to this exist (e.g., 'blocky' inversion), and, as the name suggests, can provide sharper interfaces. However, they can suffer from lack of robustness. This, coupled with the widespread availability and use of smoothness-type inversions for ERT, led to the adoption here of this approach. For 2D modelling, we used the code R2 (Binley 2013), and for 3D modelling, we adopted the code R3t (Binley 2013). Both codes utilize an unstructured finite-element mesh, allowing modelling and representation of complex geometries. Much of the modelling was carried out in 3D, as the exposed face needs to be accounted for, since it acts as a resistive feature orthogonal to the ERT survey line, and therefore, the assumption of two-dimensionality is inappropriate.

\section{Soil-rock interface collection}

At each field profile, photographs of the face were obtained, and these were then geo-referenced in ArcGIS based on direct measurements of sections of the profile. Once georeferenced, an interface was manually picked and extracted from the image. This was then compared with the resistivity profile computed at the position of the ERT survey line.

\section{Synthetic profile}

For testing the ERT inversion model, a synthetic soil and rock distribution in an exposure profile was constructed (Fig. 3). In this profile, which is based on typical profiles observed locally, the average thickness of the soil layer is set to $78 \mathrm{~cm}$ with a standard deviation of $50 \mathrm{~cm}$. Variation 


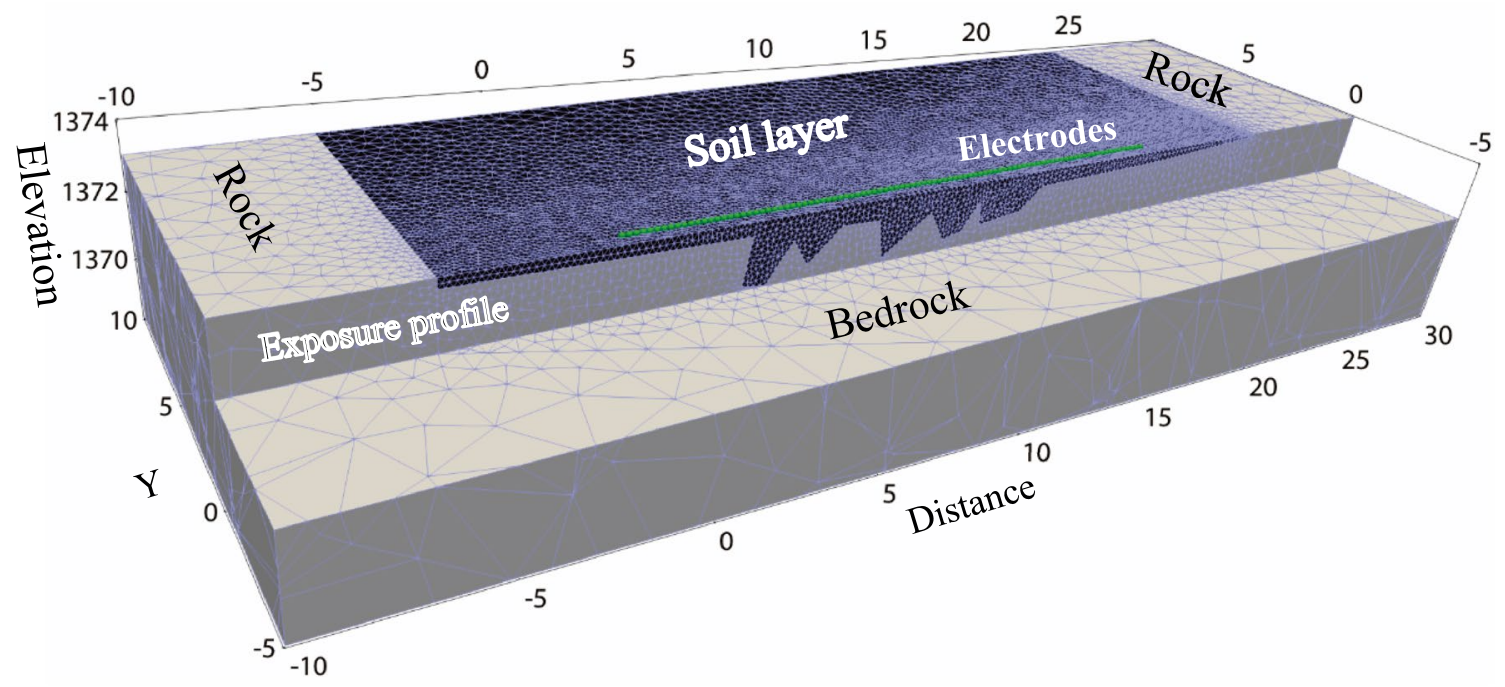

Fig. 3 Synthetic model showing soil layer overlying bedrock on an exposure profile

in soil thickness was added to mimic soil within vertical fissures in bedrock. We assume that the soil distribution in the direction orthogonal to the ERT survey is constant. The height of the exposed profile is set to $2 \mathrm{~m}$. The resistivity of soil and bedrock is set to 20 and $2000 \Omega \mathrm{m}$, respectively (see, for example, Glover 2015). The ERT survey contains 96 electrodes at $20 \mathrm{~cm}$ spacing and runs parallel to the exposed profile, $50 \mathrm{~cm}$ from the exposed face.

Given the exposed profile in Fig. 3, an unstructured 3D finite-element mesh was created to represent the geometry of the site. The 3D code, R3t, was used, in forward mode, to compute the voltages from dipole-dipole measurements along the single ERT transect, i.e., the modelled ERT data. Measurements were made with different dipole spacing: "skip 0" (dipole spacing of one electrode, i.e., $20 \mathrm{~cm}$ ), "skip 2" (dipole spacing of three electrodes), and "skip 8" (dipole spacing of nine electrodes). Measurements were simulated for $1,2, \ldots, 20$ levels, where each 'level' is a separation between current and potential dipoles. Given the 'observed' data, R3t was then used, in inverse mode, to compute the resistivity (inverse) model that is consistent with the observed voltage signals.

The synthetic data set allowed the examination of various factors on the recovery of a reasonable representation of the soil profile: the impact of measurement error; the effect of ignoring the exposed face; the effect of choice of dipole spacing; and the effect of the choice of electrode spacing.

\section{Effect of measurement error}

In a synthetic model, there are no measurement errors, unlike a real field situation. However, measurement (and modelling) errors can impact significantly on the computed resistivity model (Tso et al. 2017). To assess this impact, we perturbed the synthetic forward response with different levels of noise, assumed normally distributed. Four cases were considered: an artificially low $0.1 \%$ noise and three more realistic cases with $2 \%, 5 \%$, and $10 \%$ noise added. We assume in each case that the noise level (i.e., the statistics of noise) is known, but the actual error on each measurement is not known, as in a real setting.

The percentage root mean square (RMS) was used to evaluate the performance of the inversion in recovering the true soil profile. RMS is defined as

$\mathrm{RMS}=100 \sqrt{\frac{1}{N} \sum_{1}^{N}\left[\frac{\left(h_{\mathrm{o}}\right)_{i}-\left(h_{\mathrm{m}}\right)_{i}}{\left(h_{\mathrm{o}}\right)_{i}}\right]^{2}}$,

where $h_{\mathrm{o}}$ is observed (i.e., the true model) depth of soil layer at location $i, h_{\mathrm{m}}$ is the model (i.e., inverted model), and $N$ is the number of observations. If RMS is equal to 0 , clearly, the model-simulated results perfectly match the observations; if RMS is greater than $100 \%$, then the model is no better than a predictor using zero (Cheng et al. 2018).

The results of the inversions of the four data sets are shown in Fig. 4. In each image, a magenta line shows the true interface and a white line shows a $32 \Omega \mathrm{m}$ resistivity 


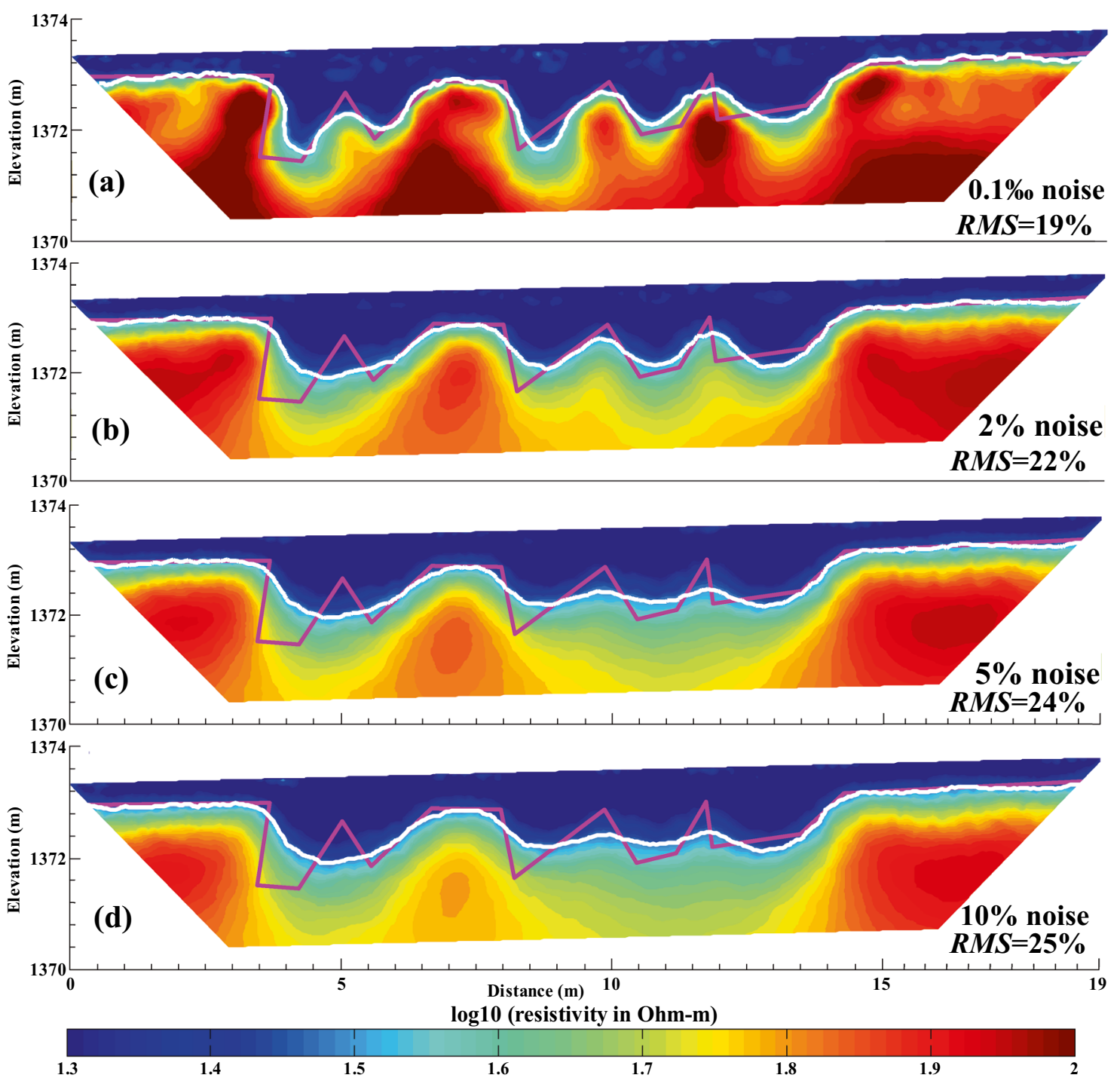

Fig. 4 Effect of measurement error level on the inverted resistivity distribution of the synthetic model. Magenta line: true interface. White line: $32 \Omega$ m contour

contour, selected as an interface between relatively lowand high-resistivity zones. The choice of such a value of resistivity is somewhat subjective, but should reflect the value of maximum change in resistivity through a vertical profile. Indeed, one may adopt more sophisticated image analysis tools to select such a region of transition of resistivity. The images show that under low measurement error, the inversion recovers significant detail about the structure of soil-bedrock interface, but as the measurement error increases, the misfit between true and modelled result increases. However, even for error levels above those normally expected in the field (e.g., Fig. 4d), a reasonable recovery of the pattern is achievable.
In practice, measurement error is estimated by the survey operator. Tso et al. (2017) provide some guidelines for such estimation and illustrate the impact of inappropriate error estimation. Figure 5 shows, for the synthetic case here, how incorrect estimation of measurement errors affects the interpreted profile. Taking the forward model in Fig. 3 and perturbing the data with $2 \%$ noise, inversions were carried out assuming an underestimated measurement error of $0.2 \%$. Figure 5 shows the result, alongside the result with a 'correct' measurement error estimate of $2 \%$ (i.e., as shown in Fig. 4b). As shown in the figure, underestimating the measurement error leads to greater lateral variation in the interpreted interface. At some locations (e.g., $\sim 5 \mathrm{~m}$ along the profile), the interface is better matched to the true model, 


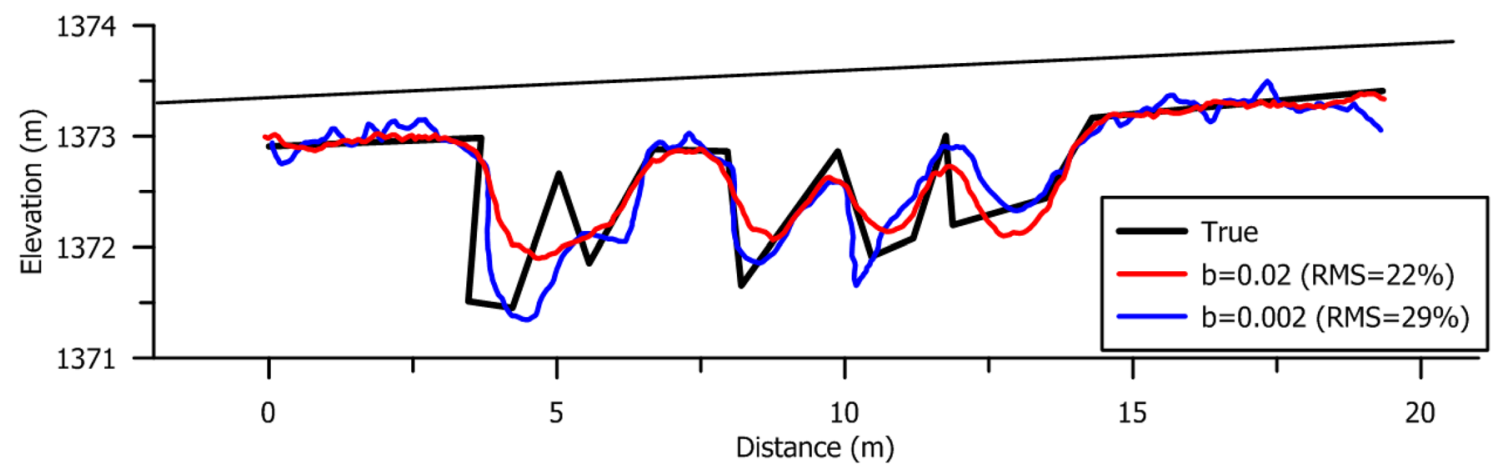

Fig. 5 Effect of assumed measurement error on inferred resistivity interface of the synthetic model

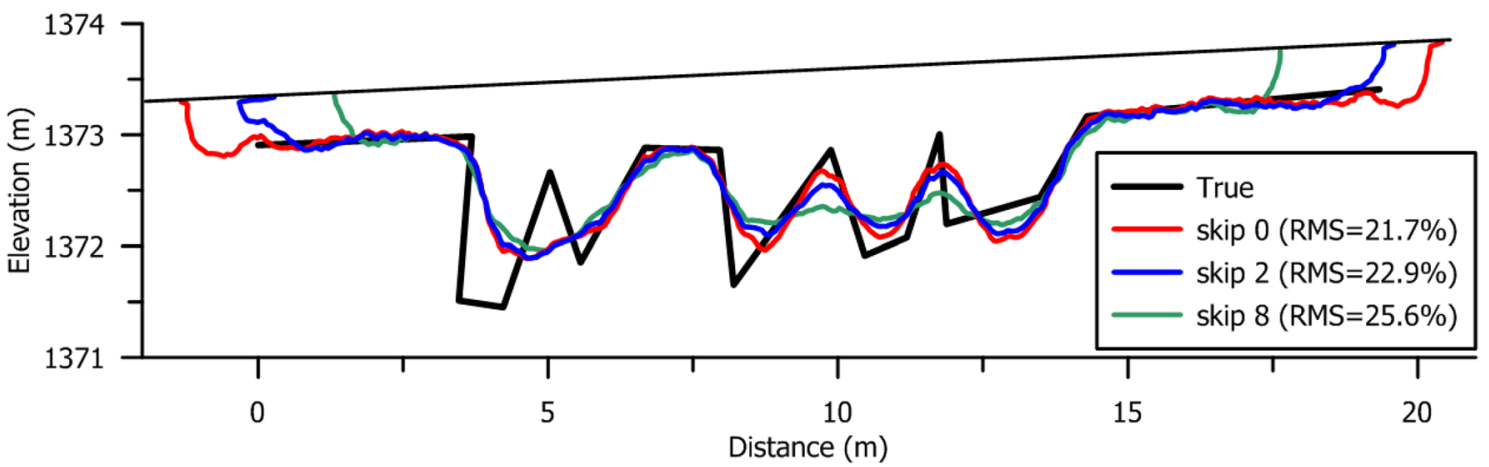

Fig. 6 Effect of dipole spacing on inferred resistivity interface of the synthetic model

but in general, there is a poorer misfit, highlighting the need to assess measurement errors in the field.

\section{Effect of different dipole-dipole configurations}

Increasing the electrode dipole spacing increases the magnitude of the measured voltage and thus will enhance the signal-to-noise ratio in a field setting. However, there is a risk of deterioration of resolving capability with a large dipole spacing. Figure 6 illustrates the performance of 3D inversions using data from the synthetic model with $2 \%$ noise using three different dipole spacing lengths. Some smearing of the interpreted interface (e.g., at $10 \mathrm{~m}$ and $12 \mathrm{~m}$ ) is evident from the skip 8 (dipole length $=1.8 \mathrm{~m}$ ) result. Clearly, it is not necessary to constrain a survey to one dipole spacing: a combination can be used to balance resolution and signal strength. However, the results do reveal some level of redundancy (e.g., the skip 0 and skip 2 results are similar), and thus, careful consideration of appropriate configurations prior to any survey is recommended. A wide range of quadrapole configurations is possible for DC resistivity surveys. The optimum choice of quadrapole geometry or combinations will depend on several factors, notably: required resolution and depth of investigation; sources of noise; instrumentation available. By examining the effectiveness of different quadrapoles through forward modelling with realistic noise incorporation, survey performance can be significantly enhanced.

\section{Ignoring the three-dimensionality of the problem}

The forward model (Fig. 3) is clearly three-dimensional in nature given the exposed face. Figure 7 illustrates the performance of a two-dimensional inversion of data from such a model. For this case, the 3D forward model data were perturbed with $2 \%$ Gaussian noise and then inverted using the $2 \mathrm{D}$ inverse code, $\mathrm{R} 2$. In comparison with the equivalent 3D inversion (Fig. $4 \mathrm{~b}$ ), the performance of the $2 \mathrm{D}$ inversion is relatively poor: the non-conducting exposed face impacts on deeper measurements (since current flow from an electrode is three-dimensional), which has an effect of adjusting the position of the interface in the inverse model, in addition to smearing some of the structure of the interface. This example is somewhat artificial, as the effect of 3D current flow is only exaggerated here because of the exposed face, which would not normally exist in a normal field application. However, the value of appropriate three-dimensional modelling 


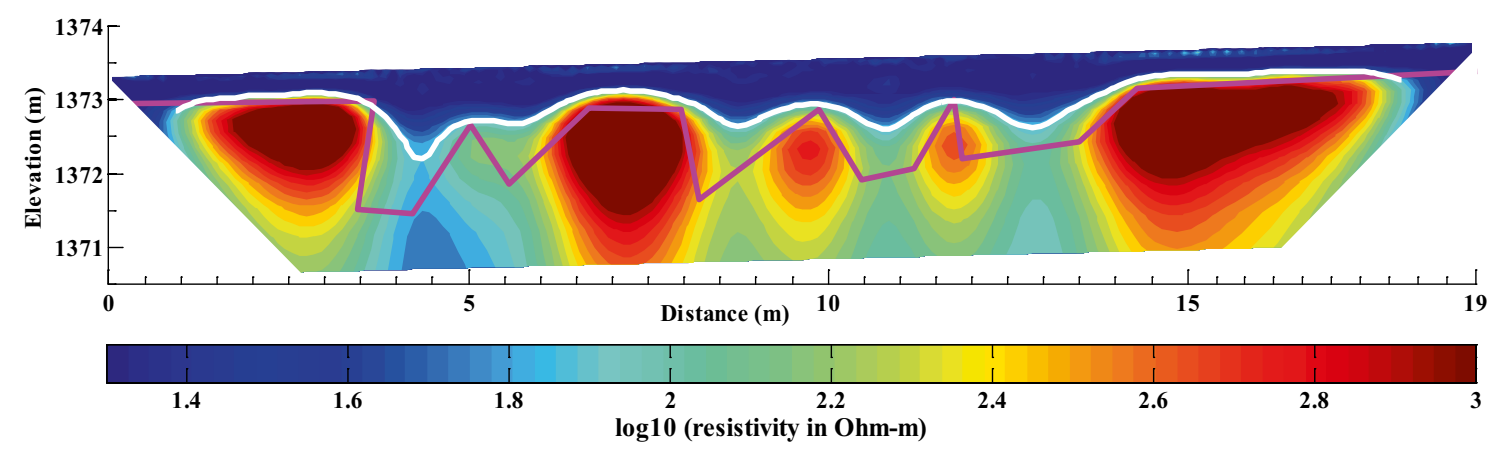

Fig. 7 Inverted resistivity distribution of the synthetic model using a 2D ERT inversion. Magenta line: true interface. White line: $77 \Omega \mathrm{m}$ contour

in inverse mode for the field data shown in the next section is clearly made.

\section{Field profiles}

\section{Thick-bedded limestone}

Two profiles with thick-bedded limestone, located in Maguan town, Puding County, were chosen (Fig. 2). The properties of the two profiles are shown in Table 1 (ID 1 and 2). Photographs of the two exposed faces are shown in Fig. 8a (ID 1) and b (ID 2). The average soil thickness in profile ID 1 is less than that of profile ID 2, but greater variation in the former is evident. The ERT survey line designs of the two profile are listed in Table 1. ERT surveys were carried out with a dipole-dipole skip 0 , skip 1 , and skip 2 configuration, which were merged prior to inversion. The measurement errors were estimated based on the difference between forward and reciprocal measurements: estimated relative errors for the two survey line are $1.6 \%$ and $0.3 \%$, respectively.

The inverted resistivity distributions from R3t are shown in Fig. 8a, b. The soil layer clearly shows up as a low resistivity zone above a high resistive bedrock. As can be seen from the resistivity models in Fig. 8, ERT is generally able to detect the location of the soil-bedrock interface, although a $200 \Omega$ m contour was selected for profile ID 1 and a $100 \Omega \mathrm{m}$ contour for profile ID 2. A contrast in resistivity is not as sharp as the photograph, which is no doubt a result of the diffusive nature of the ERT method coupled with smoothing to regularize the inversion. Note also that the ERT measurements were carried out along a single transect and although the three-dimensional nature of current flow in the profile is modelled and the image shown is a two-dimensional vertical slice of the three-dimensional inversion, any resistivity variation orthogonal to the survey line cannot be accounted for. Despite these limitations, and recognizing that our goal is not to reproduce perfectly the interface, the ERT inversions reveal clearly that soil extending to depths of over $1 \mathrm{~m}$ exist at the site.

\section{Dolostone}

Two dolostone profiles, located downstream of the Qinshan reservoir, were selected (Fig. 2). Photographs of the profiles are shown in Fig. 9. The characteristics of the two profiles are reported in Table 1 (ID 3 and 4). Profile ID 3 (Fig. 9a) shows significant lateral variability and deep soil infill, whereas profile ID 4 (Fig. 9b) is characterized by relatively thin soil with a reasonable flat bedrock interface. At the lefthand side of profile ID 3, a karst void is apparent, which connects to the surface via a sinkhole.

The ERT survey line designs, layout, and arrays are shown in Table 1 (ID 3 and 4). Again, measurement errors, based on reciprocity, were low: $0.1 \%$ and $0.5 \%$, respectively, for ID 3 and ID 4. The resistivity models computed by R3t are shown in Fig. 9. As in the previous limestone example, a contrast in bedrock and soil resistivity of about one order of magnitude is evident. A resistivity contour of $100 \mathrm{Ohm} . \mathrm{m}$ was used to demark a soil-bedrock interface. Again, the general pattern is recovered by the resistivity model, although the smaller scale features are poorly resolved (e.g., 10-15 m along profile ID 3 in Fig. 9a). The deeper feature towards the left-hand side of profile ID 3 is clearly not accurately reproduced by the inversion, but the resistivity model does reveal low resistivity to depth-consistent with the observed terra rossa profile. For profile ID 4, a relatively low resistive feature is also seen at depth on the left-hand side of the profile ( $\sim \mathrm{m}$ along the profile), which appears inconsistent with the marked interface on the image (Fig. 9b); however, as can be seen from the photograph, there is evidence of some deeper clay soil at this point.

\section{Laminar-bedded limestone}

A laminar-bedded limestone profile located at Shirenzai (Fig. 2) was selected for investigation. Figure 10 shows a 
(a)
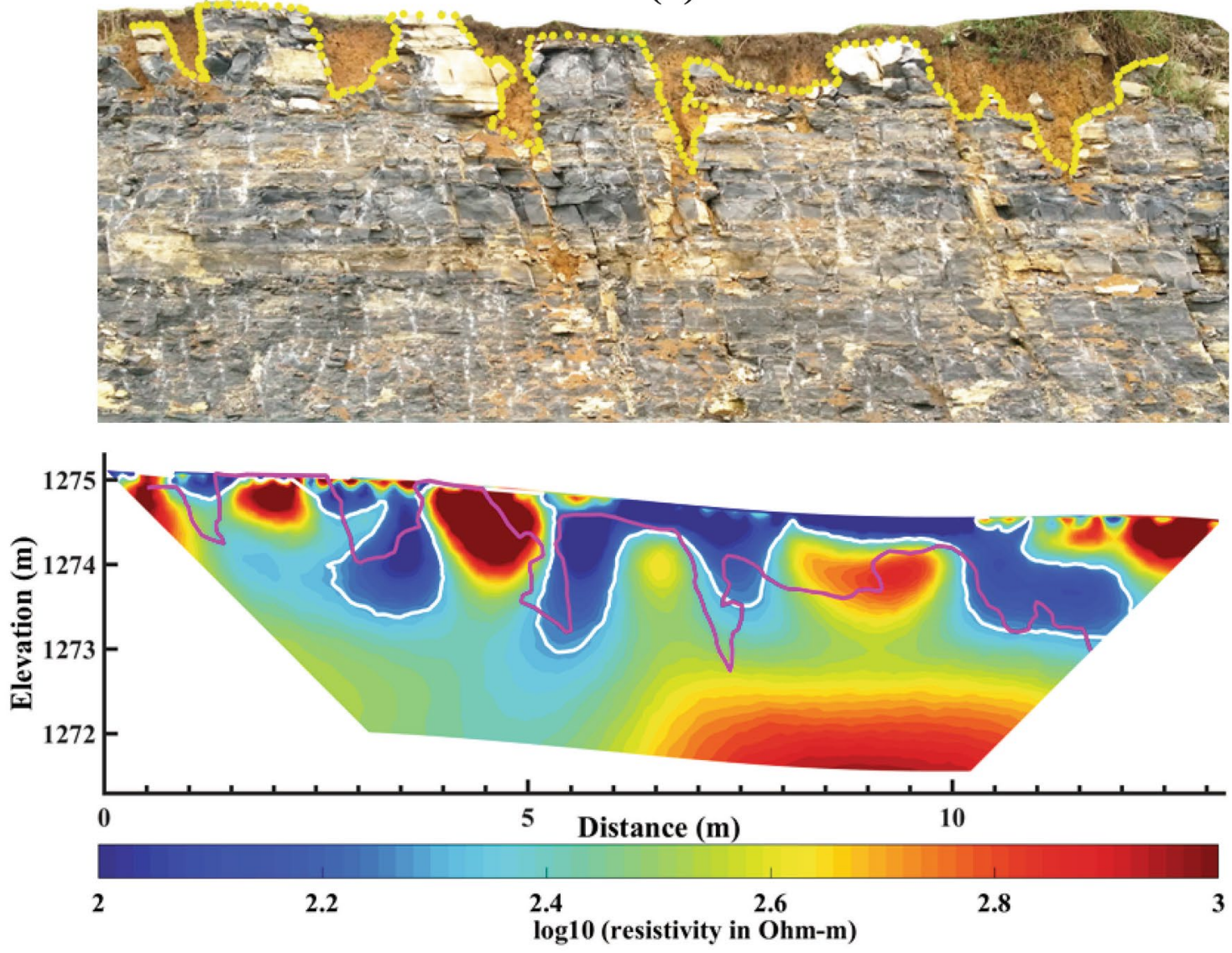

(b)

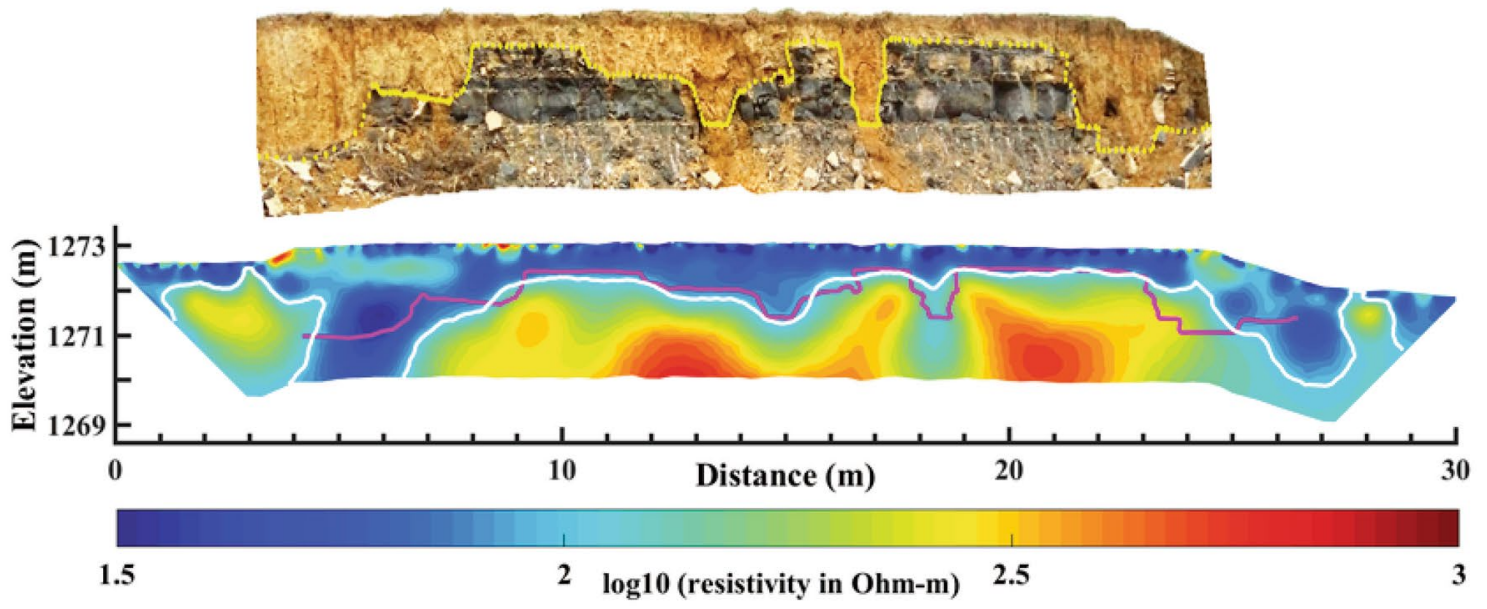

Fig. 8 Example profiles and ERT-resistivity model for the Maguan limestone site. Yellow line (photo) and magenta line (ERT image): true interface. White line: inferred interface from ERT. a Profile ID1;

photograph of the exposed profile; features of the profile and ERT survey are reported in Table 1 (ID 5). In this profile, the soil layer is undulatory, but in some parts, the soil b Profile ID2 (see Table 1 for details). The horizontal and vertical scales of the photo are identical to that of the image accompanying it

thickness is large (up to $2 \mathrm{~m}$ ) due to deep solution fissures. ERT measurement errors were generally very low, resulting 
(a)

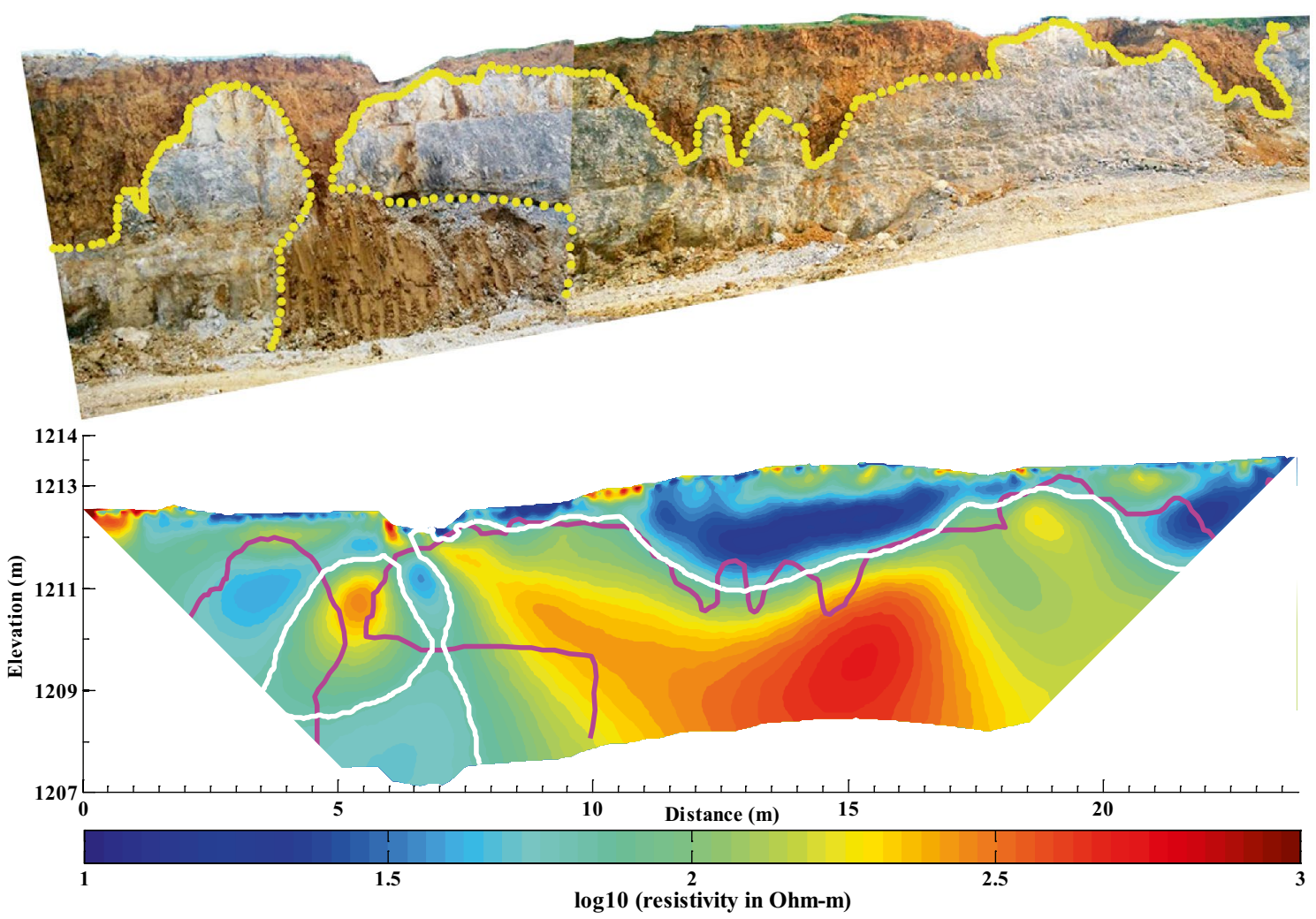

(b)
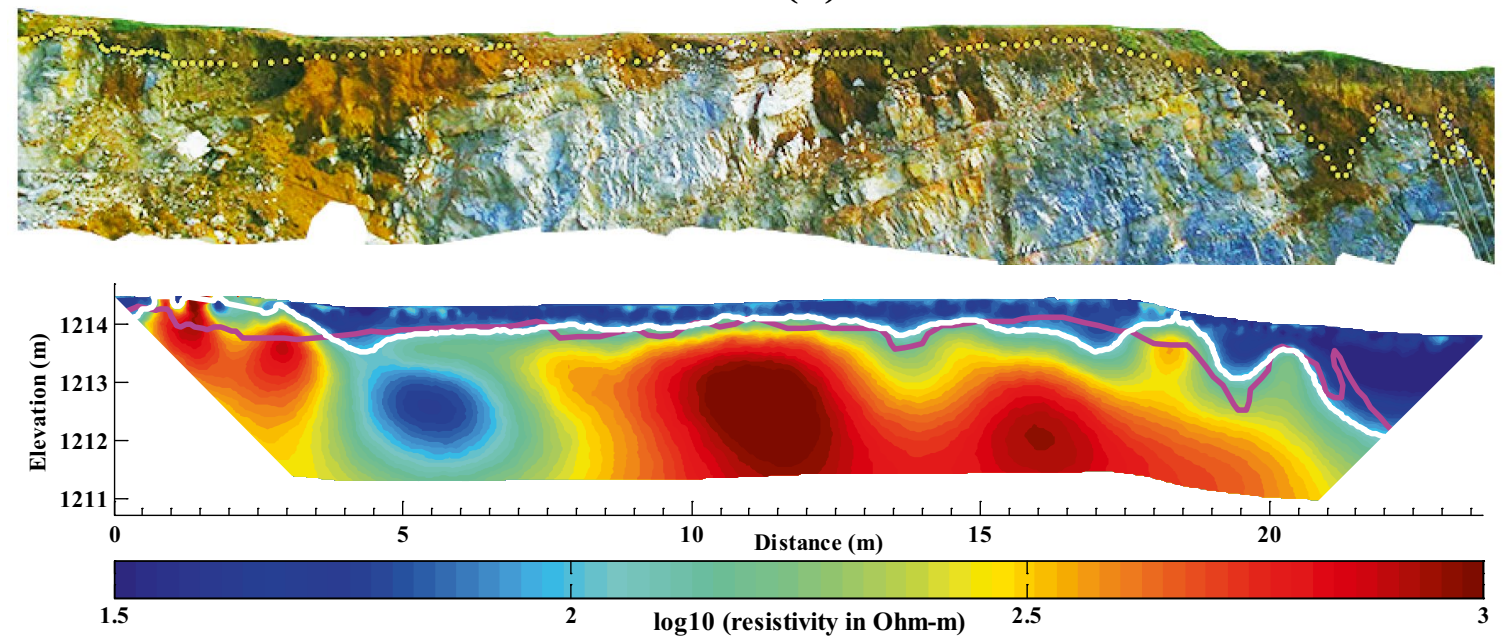

Fig. 9 Example profiles and ERT-resistivity model for the dolostone site. Yellow line (photo) and magenta line (ERT image): true interface. White line: inferred interface from ERT. a Profile ID3; b Profile

in a relative error estimate of $0.8 \%$. The inverted resistivity model from R3t is shown in Fig. 10.

The resistivity model, again, shows consistency with the profile. Although specific individual fissures cannot be resolved, the depth of clay and contrast between left- and
ID4 (see Table 1 for details). The horizontal and vertical scales of the photo are identical to that of the image accompanying it

right-hand sides of the profile mirrors the profile well. The zone of relatively high $(1000 \Omega \mathrm{m})$ resistivity on the right of the image matches the observed intact bedrock; however, the bedrock on the left of the profile appears to have somewhat lower resistivity. This highlights a challenge in areas, where 


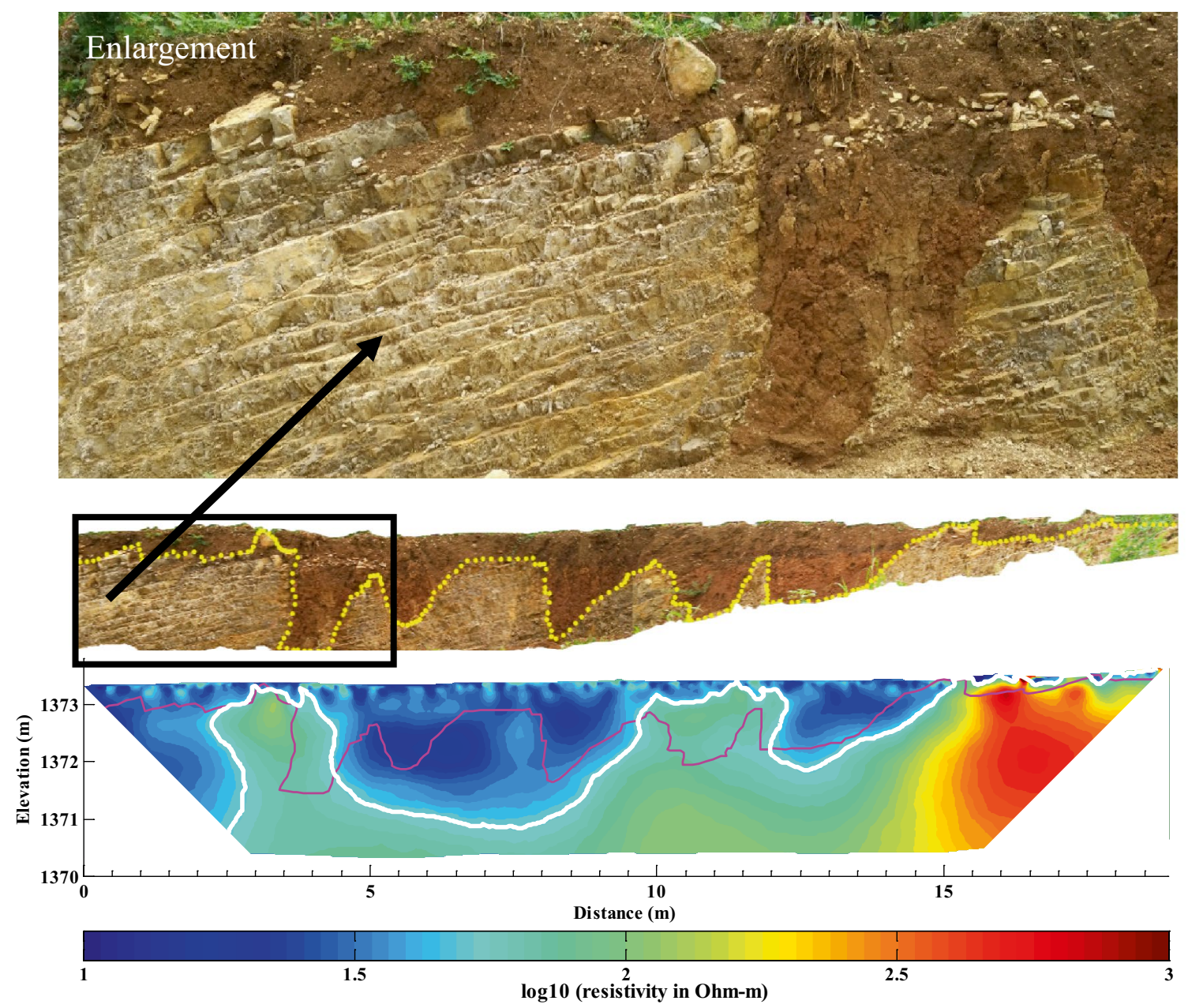

Fig. 10 Example profile and ERT-resistivity model for the laminarbedded limestone site (ID5 in Table 1). Yellow line (photo) and magenta line (ERT image): true interface. White line: inferred inter-

heterogeneity of the underlying bedrock exists when such heterogeneity can lead to contrasts in electrical properties, e.g., due to local variations in lamination or occurrence of marl, for example, that may result in greater moisture retention in bedrock.

\section{Discussion}

The synthetic and field examples shown above reveal how resistivity imaging may be effective in revealing complex morphology of a shallow soil-bedrock interface in karstic environments. Such soil may be localized infill or due to replacement of carbonate rocks by minerals forming terra rossa soils. In-situ demonstration of such techniques is challenging because of the high heterogeneity in such systems and limited direct observations. Our approach has been to exploit the existence of exposed faces as field face from ERT. The horizontal and vertical scales of the photo are identical to that of the image accompanying it

laboratories. Visual inspection of these faces provides a powerful means of validation; however, we can only assess structures visually at the face and yet we know that the systems are highly heterogeneous and any variation orthogonal to the face is impossible to quantify. As techniques such as ERT are sensitive, to some degree, to such variation, particularly as dipole separation increases, then the image represents an aggregation of this larger footprint, which may differ from that revealed on the exposed face. As our study has focused on exposed faces, threedimensional geo-electrical modelling was necessary. For practical application, conventional two-dimensional approaches would be adopted.

Despite these limitations, the resistivity images reported here reveal, in general, significant consistency with the observed structures. We rely, of course, on contrasts between electrical resistivity of unconsolidated materials and bedrock. In the sites, we have worked on the Puding County 
of Guizhou Province, China, and aquifer potentiometric surfaces are relatively low and soils relatively thin, and so, such contrast exists. For sites with infill extending beneath a potentiometric surfaces, contrasts in resistivity will be weaker and the technique less effective. In such cases, a combination of different quadrupole geometries may be more effective, thus retaining some lateral sensitivity whilst also achieving good signal strength in deeper measurements (see, for example, May and Brackman 2014).

The ERT results from synthetic and field trials reported here indicate that despite short electrode spacing (typically $10 \mathrm{~s}$ of $\mathrm{cm}$ ) and good measurement quality, a perfect delineation of a soil-bedrock interface in such environments is unlikely to be achieved. ERT, as a potential field problem, will never provide such delineation. As we have adopted conventional smoothness-based inverse modelling approaches, sharp contrasts in resistivity are penalized to some degree by the adopted objective function of the inverse method. Alternative inverse methods exist that can lead to sharper contrasts in the inverse model; however, we elected to use a smoothness-based approach because of their inherent robustness and universal adoption. Furthermore, we believe that there is a greater value in the ability to estimate (1) whether such terra rossa exists; (2) what the typical vertical and length scales of such terra rossa are; and (3) an estimate of the total soil stock within an area. Based on the results shown above, it would appear that such assessments are achievable.

Alternative geophysical methods exist that may be effective for similar application. Ground penetrating radar (GPR) is a likely contender and is certainly capable of much high resolution (with appropriate antennae) (e.g., Carrière et al. 2013). In fact, at the field sites reported here, we also ran GPR surveys, but the results were generally inconclusive due to numerous vertical and horizontal reflections sources. In addition, clay soils are often, so conductive that georadar energy does not penetrate deep enough. That is not to say that GPR would not work in other sites, but for the five field profiles reported, GPR was ineffective.

As always, geophysical methods should not be used in isolation. Here, we have compared visually with exposed faces. In a true field deployment, such faces will clearly not exist and other means of local validation will be required. This is likely to be in the form of shallow drilling or (much easier) penetrometer testing.

The surveys employed here used relatively short electrode spacing to delineate features over the scale of $1 \mathrm{~m}$ or greater. Clearly, for application over larger field sites, such deployment is likely to be impractical using the same configuration. However, advances in geophysical techniques applied to agronomy (Allred et al. 2008) may have potential for such larger scale investigations. In fact, there has been a recent regeneration of the use of terrain conductivity (electromagnetic induction, EMI) measurements in agronomy and soil science (e.g., Corwin and Lesch 2005), which may prove effective for shallow karst deployment. Such measurements are made using induced currents and thus do not rely on physical contact with the soil (as in the case of ERT); furthermore, these measurements are relatively rapid, allowing easy coverage of large areas with a single operator. New EMI instruments are available with multiple-coil spacing, allowing concurrent assessment of electrical resistivity at different depths (e.g., von Hebel et al. 2014; Shanahan et al. 2015). Although resolution will be even weaker than ERT, these methods may be extremely effective at assessing first order estimates of soil stocks, perhaps used in combination with ERT to provide localized higher resolution at targeted areas. As we move to even larger scales, resistivity imaging offers great potential for validating remote sensed data (e.g., from satellite data), as demonstrated recently by Pardo-Igúzquiza et al. (2018).

\section{Conclusion}

This study has shown how ERT can be used effectively to assess the soil-rock interface in karstic environments. The inverted results based on the synthetic data show that the accuracy of the delineation of the soil-rock interface decreases with the increase of measurement error, and dipole spacing. Reliable estimation of measurement error is important for quantitative assessment of the soil-bedrock boundary - a factor that has often been overlooked in earlier, related, studies.

Unlike previous field-based studies utilizing point-based observations of soil thickness (e.g., from boreholes), this study exploited the availability of a number of exposed faces, offering visual evidence of soil thickness and its variation along a profile. Field-based applications of ERT at five profiles in the study in southwest China have shown that: (1) ERT is able to detect horizontal or gently dipping soil-rock interfaces correctly; (2) soils stored in localized fissures, solution-enlarged joints, or grikes can be detected, but resolution can be limited; (3) the lateral boundary of a soil-filled fissure is clearer than the bottom boundary, because the lateral resolution of dipole-dipole method adopted here; (4) ERT is unable to detect small fissures under the thick soil layer; and (5) if the bedrock is weakly resistive [as observed at the lamellar limestone site possibly because of intense weathering and combination of high water and clay content (Fig. 10)], then differentiation of the soil-rock interface may be challenging.

Some improvements in ERT performance may be possible through more sophisticated inverse modelling, but these must be robust for wide deployment. However, we firmly believe that as a means of assessing general features and 
nature of the soil-bedrock interface patterns non-invasively, ERT is an effective tool. Furthermore, used in conjunction with mobile electromagnetic induction instruments, total soil stocks over karst landscapes may be achievable. Such approaches may help us, as we seek to quantify the vulnerability or resilience of this important landscape to anthropogenic and natural stresses.

Acknowledgements This research was supported by the UK Natural Environment Council (NERC) Grant NE/N007409/1 awarded to Lancaster University. Additional support was provided by the National Natural Science Foundation of China under the UK-China Critical Zone Observatory (CZO) Programme (41571130071 and 41601013 and 41571020), and the Jiangsu Provincial Natural Science Foundation of China (BK20150809). We are grateful to Paul Mclachlan (Lancaster University) for his production of Fig. 1. We also acknowledge comments from M.T. May and an anonymous reviewer that helped improve the manuscript. Field and model data are available from the corresponding author on request.

Open Access This article is distributed under the terms of the Creative Commons Attribution 4.0 International License (http://creativeco mmons.org/licenses/by/4.0/), which permits unrestricted use, distribution, and reproduction in any medium, provided you give appropriate credit to the original author(s) and the source, provide a link to the Creative Commons license, and indicate if changes were made.

\section{References}

Allred B, Daniels JJ, Ehsani MR (2008) Handbook of agricultural geophysics. CRC Press, Boca Raton

Banerjee A, Merino E (2011) Terra rossa genesis by replacement of limestone by kaolinite. III. Dynamic quantitative model. J Geol 119(3):259-274

Binley A (2013) R3t version 1.8 manual. Lancaster University, Lancaster. http://www.es.lancs.ac.uk/people/amb/Freeware/R3t/R3t. htm. Accessed 17 Aug 2017

Binley A (2015) Tools and techniques: DC electrical methods. In: Schubert G (ed) Treatise on geophysics, vol 11, 2nd edn. Elsevier, New York, pp 233-259

Binley A (2016) R2 version 3.1 manual. Lancaster. http://www.es.lancs .ac.uk/people/amb/Freeware/R2/R2.htm. Accessed 17 Aug 2017

Binley A, Kemna A (2005) DC resistivity and induced polarization methods. In: Rubin Y, Hubbard SS (eds) Hydrogeophysics. Water science and technology library, vol 50. Springer, Dordrecht

Binley A, Hubbard SS, Huisman JA, Revil A, Robinson DA, Singha K, Slater LD (2015) The emergence of hydrogeophysics for improved understanding of subsurface processes over multiple scales. Water Resour Res 51(6):3837-3866. https://doi.org/10.1002/2015W R017016

Carrière SD, Chalikakis K, Sénéchal G, Danquigny C, Emblanch C (2013) Combining electrical resistivity tomography and ground penetrating radar to study geological structuring of karst unsaturated zone. J Appl Geophys 94:31-41

Chalikakis K, Plagnes V, Guerin R, Valois R, Bosch FP (2011) Contribution of geophysical methods to karst-system exploration: an overview. Hydrogeol J 19(6):1169-1180

Cheng Q-B, Chen X, Xu C-Y, Reinhardt-Imjela C, Schulte A (2018) Using maximum likelihood to derive various distance-based goodness-of-fit indicators for hydrologic modeling assessment. Stoch Env Res Risk Assess 32:949-957

Corwin DL, Lesch SM (2005) Apparent soil electrical conductivity measurements in agriculture. Comput Electron Agric 46:11-43

Fu Z, Chen H, Xu Q, Jia J, Wang S, Wang K (2016) Role of epikarst in near-surface hydrological processes in a soil mantled subtropical dolomite karst slope: implications of field rainfall simulation experiments. Hydrol Process 30(5):795-811

Glover PWJ (2015) Geophysical properties of the near surface earth: electrical properties. In: Schubert G (ed) Treatise on geophysics, vol 11, 2nd edn. Elsevier, Oxford, pp 89-137

Goldscheider N, Drew D (eds) (2007) Methods in karst hydrogeology International contributions to hydrogeology, vol 26. Taylor \& Francis, London

Hollingsworth E (2009) Karst Regions of the World (KROW) - populating global karst datasets and generating maps to advance the understanding of karst occurrence and protection of karst species and habitats worldwide. University of Arkansas, Fayetteville. $24 \mathrm{pp}$

Hu K, Chen H, Nie Y, Wang K (2015) Seasonal recharge and mean residence times of soil and epikarst water in a small karst catchment of southwest China. Sci Rep 5:10215. https://doi.org/10.1038/ srep10215

Jiang ZC, Lian YQ, Qin XQ (2014) Rocky desertification in Southwest China: impacts, causes, and restoration. Earth Sci Rev 132:1-12

Kaufmann O, Deceuster J (2014) Detection and mapping of ghost-rock features in the Tournaisis area through geophysical methods: an overview. Geol Belg 17(1):17-26

Keshavarzi M, Baker A, Kelly BF et al (2017) River-groundwater connectivity in a karst system, Wellington, New South Wales, Australia. Hydrogeol J 25(2):557-574

Martínez-Moreno FJ, Galindo-Zaldívara J, Pedrera A, Teixido T, Ruano P, Peña JA, González-Castillo L, Ruiz-Constán A, LópezChicanoa M, Martín-Rosalesa W (2014) Integrated geophysical methods for studying the karst system of Gruta de las Maravillas (Aracena, Southwest Spain). J Appl Geophys 107:149-162

May MT, Brackman TB (2014) Geophysical characterization of karst landscapes in Kentucky as modern analogs for paleokarst reservoirs. Interpretation 2(3):SF51-SF63

Merino E, Banerjee A (2008) Terra rossa genesis, implications for karst, and eolian dust: a geodynamic thread. J Geol 116(1):62-75

Miller A (1953) The skin of the earth, 1st edn. Methuen, London, p 198

Pardo-Igúzquiza E, Dowd PA, Ruiz-Constán A, Martos-Rosillo S, Luque-Espinar JA, Rodríguez-Galiano V, Pedrera A (2018) Epikarst mapping by remote sensing. CATENA 165:1-11

Peng T, Wang SJ (2012) Effects of land use, land cover and rainfall regimes on the surface runoff and soil loss on karst slopes in southwest China. CATENA 90:53-62

Schoonover JE, Crim JF (2015) An introduction to soil concepts and the role of soils in watershed management. J Contemp Water Res Educ 154(1):21-47

Shanahan P, Binley A, Whalley R, Watts C (2015) The use of electromagnetic induction to monitor changes in soil moisture profiles beneath different wheat genotypes. Soil Sci Soc Am J 79(2):459-466

Sweeting MM (1995) Karst in China: its geomorphology and environment. Springer, Berlin, p 265

Tso C-H, Kuras O, Wilkinson PB, Uhlemann S, Chamber JE, Meldrum PI, Graham J, Sherlock EF, Binley A (2017) Improved characterisation and modelling of measurement errors in electrical resistivity tomography (ERT) surveys. J Appl Geophys 146:103-119

von Hebel C, Rudolph S, Mester A, Huisman JA, Kumbhar P, Vereecken H, van der Kruk J (2014) Three-dimensional imaging of subsurface structural patterns using quantitative large-scale 
multiconfiguration electromagnetic induction data. Water Resour Res 50:2732-2748

Wang SJ, Liu QM, Zhang DF (2004) Karst rocky desertification in southwestern China: geomorphology, landuse, impact and rehabilitation. Land Degrad Dev 15:115-121

Wang J, Zou B, Liu Y, Tang Y, Zhang X, Yang P (2014) Erosion-creepcollapse mechanism of underground soil loss for the karst rocky desertification in Chenqi village, Puding county, Guizhou, China. Environ Earth Sci 72(8):2751-2764

Wang S, Chen H, Nie Y et al (2015) Estimation of thickness of a soil layer on typical karst hillslopes using a ground penetrating radar. Acta Pedol Sin 52(5):1024-1030 (in Chinese)

Xia Y-H, Li L, Deng S-H, Chen X-B et al (2016) Detection of soil depths and distribution using ground penetrating radar technology in karst peak-cluster depression area. Bull Soil Water Conserv 36(1):129-135 (in Chinese)

Yan Y, Dai Q, Jin L, Wang X (2019) Geometric morphology and soil properties of shallow karst fissures in an area of karst rocky desertification in SW China. CATENA 107:48-58

Zhang Z, Chen X, Chen X, Shi P (2013) Quantifying time lag of epikarst-spring hydrograph response to rainfall using correlation and spectral analyses. Hydrogeol J 21(7):1619-1631
Zhang C, Qi X, Wang K, Zhang M, Yue Y (2017) The application of geospatial techniques in monitoring karst vegetation recovery in southwest China: a review. Prog Phys Geogr 41(4):450-477

Zhou W, Beck BF, Stephenson JB (2000) Reliability of dipole-dipole electrical resistivity tomography for defining depth to bedrock in covered karst terranes. Environ Geol 39(7):760-766

Zhou J, Tang Y, Yang P, Zhang X, Zhou N, Wang J (2012) Inference of creep mechanism in underground soil loss of karst conduits I. Conceptual model. Natural hazards 62(3):1191-1215

Zhu J, Currens J-C, Dinger J-S (2011) Challenges of using electrical resistivity method to locate karst conduits-a field case in the Inner Bluegrass Region, Kentucky. J Appl Geophys 75:523-530

Publisher's Note Springer Nature remains neutral with regard to jurisdictional claims in published maps and institutional affiliations. 